\title{
Sustainable Power for Carbon Neutral Operation: A Feasibility Study for Printing Industry in Sri Lanka
}

\author{
Archishman Bose', Kiran Raj Rajan' ${ }^{1}$, Ruchira Abeyweera ${ }^{2}$, Janaka Rathnakumara ${ }^{3}$, N.S. Senanayake ${ }^{2}$, \\ Tharanga Wicramarathna ${ }^{4}$, Jeevan Jayasuriya ${ }^{5}$ \\ ${ }^{1}$ MSc. SELECT: InnoEnergy, KTH Royal Institute of Technology, Sweden/ Politecnico di Torino, Italy, 2 The Open \\ University Sri Lanka, Sri Lanka, ${ }^{3}$ Wijeya Newspapers Limited, WNL, Sri Lanka, ${ }^{4}$ Ceylon Electricity Board, Sri \\ Lanka, ${ }^{5}$ EIT InnoEnergy, Sweden, KTH Royal Institute of Technology, Sweden
}

\begin{abstract}
A leading printing company in Sri Lanka was selected to evaluate the techno-economic feasibility of renewable power generation to de-carbonize the (low carbon) operations. The study critically looked at the resource, economic and social factors affecting the design of a grid integrated renewable power system in a rural area. Technical challenges of grid integration through fluctuating renewable power along with economic challenges were investigated. Connecting to the closest $33 \mathrm{kV}$ bus was considered the most viable grid interconnection option.
\end{abstract}

The study indicated that a standalone Photovoltaic System (PV) of $4 \mathrm{MW}$ would be necessary to generate the $5.2 \mathrm{GWh} /$ year requirement by the printing facility. To take advantage of the current $60 \mathrm{MW}$ grid connected competitive tender based Solar PV project by the Ceylon Electricity Board, a detailed techno-economic assessment was conducted for a grid connected 1MW system. A tariff of $19.48 \mathrm{LKR} / \mathrm{kWh}$ would result in a payback period of around 5 years with a reduction of 1068 tons of $\mathrm{CO}_{2}$ emission per year. Since the project location is within the coconut plantation belt of Sri Lanka, and because of attractive tariff schemes for bio-power, feasibility of a hybrid power system with biomass was also carried out. Different combinations of solar PV-biomass based hybrid solutions were studied within a maximum capacity of $3 \mathrm{MW}$ due to space constraints. This results in a considerably reduced tariff, as low as 10 LKR/kWh, while maintaining a constant payback period of 5 years. A 2 MW hybrid system incorporating solar photovoltaic and biomass gasification, $1 \mathrm{MW}$ each, is proposed to be the most economical solution, with project capital expenditure of 2.45 million USD.

The operation strategy of the proposed hybrid system could ensure a stable power output of 1 MW at the capacity factor of at least $75 \%$ of the year, compared with $17.53 \%$ for a $1 \mathrm{MW}$ Solar Photovoltaic power system.

\section{Introduction}

In addition to implementing sustainable practices for improvement in energy efficiency, medium to small scale industries have begun to produce their own green energy. However, challenges remain. Optimal selection of technologies and size of power generation units is not only driven by technical and economic aspects, but also by local laws and resource availability [1]. Ease of implantation also plays a crucial role in such projects, especially for an industry without any expertise on electricity generation.

Sri Lanka's energy mix has been dominated over the years by hydro power generation. However, with the increase in demand and the saturation of hydro power, coal has recently been added to the energy mix, with a 900MW power plant (Ministry of Power and Renewable Energy, n.d.) that was completed in 2014. Furthermore, with oil being phased out as a source of energy for electricity generation, coal is set to become the major source of electricity in Sri Lanka. Future scenarios predict that the percentage of coal power will continue to rise (Jayasekera, 2014) and may even reach $40 \%$ by 2020 and $60 \%$ by 2034 (Ceylon Electricty Board, 2016).

The life cycle analysis of newspaper printing has been studied with published reports [4]. The primary energy source for newspaper printing and other related processes is electricity. The national grid inherently has its own specific emissions due to the presence of fossil fuel power generation units [5]. Hence the use of electricity naturally results in net carbon emissions from printing operations. The generation of own power from renewable energy resources would, therefore, result in a decrease of emissions from the printing process.

A leading newspaper company in Sri Lanka was selected to evaluate the techno-economic feasibility of renewable power generation to de-carbonize its operations. The industry selection was based on it being representative of a typical medium scale industry. The present annual energy demand for printing daily newspapers and magazines is 3.5 GWh. However, with a planned $30-40 \%$ expansion, by 2020 , the annual energy requirement has been predicted to be $5.2 \mathrm{GWh}$. Further, printing as an industry has reached its peak growth in many 
countries [6]. In Sri Lanka, it is predicted to reach its peak in 10-15 years' time [7]. Hence, diversification of the business of the printing company was considered as well. Accordingly, a feasibility study on the concept of power generation was carried out.

The overall objective of this study was to determine the techno-economic feasibility of generating power for own energy needs of the factory by using renewable technologies, and to design an energy system by determining feasible renewable energy technologies, country energy policies for Independent Power Producers (IPPs) and limitations of the company or resources available for the project.

\section{Limitations and Assumptions}

The power generation facility studied for feasibility is essentially an on-grid system. The system design hence was not based on the real-time load requirement of the printing process but meeting the annual demand of $5.2 \mathrm{GWh}$ required for the printing operations. However, future possibilities of incentives from load following and grid frequency control were considered while selecting the power generation technologies. Following assumptions were also made in the study.

- Timeframe of project implementation was considered as 2020.

- Life cycle emissions were not considered in power plant related emissions. For example, emissions from solar based power systems were considered zero.

- A lifetime of 20 years was considered for all project solutions.

- A reduction of $0.7 \%$ output capacity per year was considered for all power generation systems.

- Alternative sites were not considered due to land issues and land costs.

- On economic aspects, the following were assumed:

Corporate tax: $10 \%$, capital insurance rate: $0.50 \%$, decommissioning factor: 5\%, inflation rate in Sri Lanka: 9.72\%, cost of equity: $16 \%$, tax holiday period: 6 years (Board of Investment of Sri Lanka, 2017), (Board of Investment of Sri Lanka , 2016).

Considering multiple constraints is essential for projects in developing countries like Sri Lanka. A financial constraint of a net project budget of 3 million USD was considered. Additionally, local policy with respect to Sri Lanka were studied to set up project boundaries.
An upper bound of $10 \mathrm{MW}$ of generating capacity was considered, based on the definition of Sri Lanka's small power producer category.

A lower bound of 5.2 GWh of annual energy needs to be produced, was considered.

Other constraints included space, local knowledge, social acceptance and ease of implementation.

\section{Feasibility Study}

Local laws and regulations were analyzed and found to be favorable for the development of renewable energy-based power generation projects in Sri Lanka. Thereafter, the potential site for the development of the project was studied.

The land for project development lies within the dry zone of the country and is located at Bingiriya in the North-Western Province of Sri Lanka. The area is essentially rural. The GPS location of the site is $7.684738^{\circ} \mathrm{N}, 79.992582^{\circ} \mathrm{E}$. The available land, measuring more than 100 acres (40 ha), comprises a tank, 30 acres (12 ha) of paddy fields and about 70 acres (28 ha) of coconut plantations. The river Deduru flows within $1 \mathrm{~km}$ from the land. However, an upstream dam results in the river to run dry most of the year. The water available thereby would mostly be from the ground water, or through additional connections of industrial water supply. The latter is however, a high cost solution for a rural area. Other analyses of roads, infrastructure, site vegetation, soil condition, surrounding locality including cultural and environmental aspects were found to favor the development of the project at the specified plot.

A feasibility study in relation to the three-major mature renewable energy technologies, namely wind, solar and biomass were carried out and presented as follows.

\section{Solar Photovoltaic:}

The solar photovoltaic (PV) is rapidly expanding in Sri Lanka owing to special government incentives and higher social acceptance [8]. Since the price of solar PV cells has reduced significantly over the years [9], solar power generation has become a promising industry.

The daily average solar insolation at the studied location is $5.42 \mathrm{kWh} / \mathrm{m}^{2} /$ day with a yearly mean daily average ambient daytime temperature ranging from $24-30{ }^{\circ} \mathrm{C}$ [10], making the site suitable for Solar PV power generation. A detailed study of the monthly solar resource shows that an annual capacity factor of $17.5 \%$ is feasible. Hence for generation of $5.2 \mathrm{GWh}$ of electricity, a $4 \mathrm{MW}$ of standalone solar PV system has been calculated to 
be suitable, including losses in transmission and distribution.

\section{Biomass Power:}

The plot lies within the coconut belt of Sri Lanka, with the possibility of a supplying feedstock for biomass power generation. However, a plantation of 70 acres is inadequate to supply a considerable amount of woody feedstock to a utility scale biomass power plant. Hence, the surrounding areas were identified as potential source of feedstock. Intercropping of coconut, especially with Gliricidia, had been studied to allow better land utilization and presents an attractive stable supply chain and feedstock for biomass-based power generation [11].

Combustion and gasification are the two commercialized technologies in Sri Lanka. However, for small-scale applications, especially for systems below 2 MW capacity, gasification power plant provides the optimum operations [12] with a relatively high efficiency, low water requirement and the possibility to expand with expansion of the supply chain, due to modularity.

Additionally, a detailed analysis of the biomass supply chain is critical. Strategies to ensure a stable supply chain for a maximum of 1.5 MW power systems were analyzed, essentially based on supply chain limitations. For a $1 \mathrm{MW}$ system, the annual fuel requirement is 5,256 thousand tonne of solid fuel, based on a feeding rate of 24 tonne/day operating at an efficiency of $20 \%$ and a capacity factor of $60 \%$. Around 670 acres of intercropped land would be required to supply the feedstock after consideration of the transportation and other losses.

The 65 acres of plantation land within the identified plot would be able to supply only $12 \%$ of the necessary feedstock required for a full output of 5.2 GWh per year from the 1MW power plant. Out growers or contract farmers have been considered as an essential part of the supply chain with the requirement to fulfil the weekly amount of feedstock. Additionally, a live storage of 3 to 10 days, based on different times of the year should also be ensured to maintain the stable operation of the biomass power plant.

A supply chain within $15 \mathrm{~km}$ radius (from the power plant) was identified to be the limiting option for supply from out growers. Economic analysis and other constraints with project feasibility showed that 500 out-growers, located within a radius of $5 \mathrm{~km}$ around the gasification unit would be ideal for a stable supply chain. The remaining $38 \%$ of the feedstock will need to be covered by bulk suppliers.
Presently, the printing industry re-sells approximately 1,200 tons of waste paper, annually. Estimates show that the cost of transportation from the printing facility to the power generation unit will be less than $0.5 \mathrm{LKR} / \mathrm{kg}$ of paper. Calculations show, that any resale price less than $27.50 \mathrm{LKR} / \mathrm{kg}$ would provide economic benefits to use the waste paper as a feedstock to the proposed power plant.

\section{Wind Power:}

Bingiriya site was found to be in an area with poor to marginal wind potential [13]. The surrounding area, as well as the designated land contains coconut plantations, over $10 \mathrm{~m}$ in height. This increases the turbulence intensity, thereby decreasing the wind speed and severely impacting the performance of wind turbines. Nearby lakes also possess a threat to migratory bird mortality. Based on technical, social and environmental aspects, the site was thus considered to be unsuitable for wind power generation.

\section{Grid Integration}

Evaluation of available options for grid connection and corresponding technological challenges were considered for the overall technical and economic feasibility of the project. All studies were based on the guidelines set by the Ceylon Electricity Board (CEB), for the grid connection of small scale power plants [14]. Along with these guidelines as per recommendations for small power producers IEEE and IEC international standards were also studied and followed to ensure power quality and reliability of the overall grid.

The land selected is in the Puttlam District, and the closest grid substation (GS) available to transfer power is Madampe $132 / 33 \mathrm{kV}$ GS, located about $25.7 \mathrm{~km}$ (direct distance) away. If a medium voltage line is to be constructed to Madampe GS alongside the existing road, the length would be around 29 $\mathrm{km}$. This would result in the cost of electrical infrastructure including transmission lines and metering equipment to be approximately 0.6 million USD, with considerable impacts on the project economic viability.

Hence, other technologically feasible and less economically challenging options were studied regarding the possibilities of grid integration. A $33 \mathrm{kV}$ medium voltage feeder connecting Madampe GS to Kuliyapitiya was found within $1 \mathrm{~km}$ from the proposed land. Length of the $33 \mathrm{kV}$ line was estimated at $500 \mathrm{~m}$. An outdoor switch yard was proposed for the interconnection. Land area required for the outdoor switch yard was estimated to be $60 \mathrm{~m}^{2}$ including outdoor transformer. The cost 
of grid connection would thus be around 12,000 USD.

Additionally, the existing $33 \mathrm{kV}$ MV line was studied to be sufficient to transfer up to $3 \mathrm{MW}$ capacity to nearest $33 / 132 \mathrm{kV}$ grid substation. The conductor type lynx (aluminium conductor steel reinforced) is already installed which can carry the additional generation ranging 40 to $45 \mathrm{~A}$ through the line any time of the day. Since the area does not have any nearby distributed generation, the connection to the $33 \mathrm{kV}$ MV line is thereby technically feasible.

\section{Hybrid Power System}

Power generation systems from a single source have their own limitations [15]. Multiple energy sources, when combined, produce further benefits, both from technology and economic points of view [16].

Hybridization of solar photovoltaic plant modules with biomass based power generation unit had been shown to complement each other to produce a stable power overcoming individual drawbacks [15]. An optimized solution had been developed for developing a hybrid grid integrated renewable power generation power plant that meets the desired demand as described above.

\section{MW Standalone Solar PV System}

The preliminary plant design of a $1 \mathrm{MW}$ on-grid solar PV system comprises a collector array in a string layout, with 3,173 of $315 \mathrm{Wp}$ poly-crystalline silicon (Si) cell modules, deployed in a fixed horizontal tilt of $10^{\circ}$. The conversion efficiency of the modules would be approximately $16.4 \%$, equipped with preliminary plant design MPPT facility corresponding to a net collector area of $6,195 \mathrm{~m}^{2}$.

The PV generated voltage of $400-440 \mathrm{~V}$ will be stepped up at the generation site and fed to the distribution voltage of $33 \mathrm{kV}$. The inverter system employed (capacity $15 \times 60 \mathrm{kWe}$ ) will have an efficiency not less than $98.5 \%$ together with an overall distribution loss of around $2 \%$. To avoid interruptions due to inverter, an extended warranty for 10 years was considered. The system was analysed to produce around 1.5 GWh of electricity, which is around $29 \%$ of the net energy requirement of $5.2 \mathrm{GWh}$.

The net capital expenditure (CAPEX) of the system would be around 0.732 million USD, an annual running cost of around 27,000 USD would be necessary. Accordingly, a capacity factor of $17.5 \%$ would result in the levelized cost of electricity production to be $0.08 \mathrm{USD} / \mathrm{kWh}$, or approximately 12.25 LKR/kWh. However, to ensure a payback period of 5 years, a tariff of $19.5 \mathrm{LKR} / \mathrm{kWh}$ had been proposed, which is lower than the limit for the highest tariff of $22 \mathrm{LKR} / \mathrm{kWh}$.

\section{Modular Biomass Gasification Power Plant}

A modular gasification unit with producer gas fired internal combustion engine-based system for combined generation of electricity and heat was selected as a suitable technology. The heat will be used for drying the biomass to the gasification requirements of moisture content.

The capacity factor of the biomass gasification unit was considered to be $60 \%$ as a conservative approach both with respect to technology, and availability and uncertainty of feedstock. Hence, a $1 \mathrm{MW}$ gasification system was just sufficient to produce the necessary $5.2 \mathrm{GWh}$ of electricity per year at a higher levelized cost of $0.14 \mathrm{USD} / \mathrm{kWh}$. The CAPEX of the system was estimated to be around 1.9 million USD, $74 \%$ of which is the cost of the module, the rest being civil, transportation, installation and soft costs.

High moisture content in feedstock is a problem for tropical countries like Sri Lanka. The relatively higher cost of the system is due to the presence of the rotary drier. Although it increases the installation cost to a considerable extent, it increases the overall efficiency by using the waste heat for drying the biomass feed.

\section{Hybrid System Sizing}

Techno-economic advantages of a hybrid power system in comparison with a standalone unit are many. For example, a hybrid power unit incorporating both the solar and biomass-based power generation within the same unit greatly reduces upfront cost of labour and site preparation than standalone systems. Moreover, the operation cost reduces to a considerable amount. Technical advantages include special benefits for fluctuating renewable energy sources such as solar PV, with relatively lower capacity factor. Coupling with a system such as biomass-based power which has a stable and a higher power output reduces the net levelized cost of electricity further. 
Figure 1 - Project Cash Flow for Different Solar PV-Biomass Gasification Hybrid Systems, where the first number refers to the installed Biomass Capacity and the second to the Solar Capacity

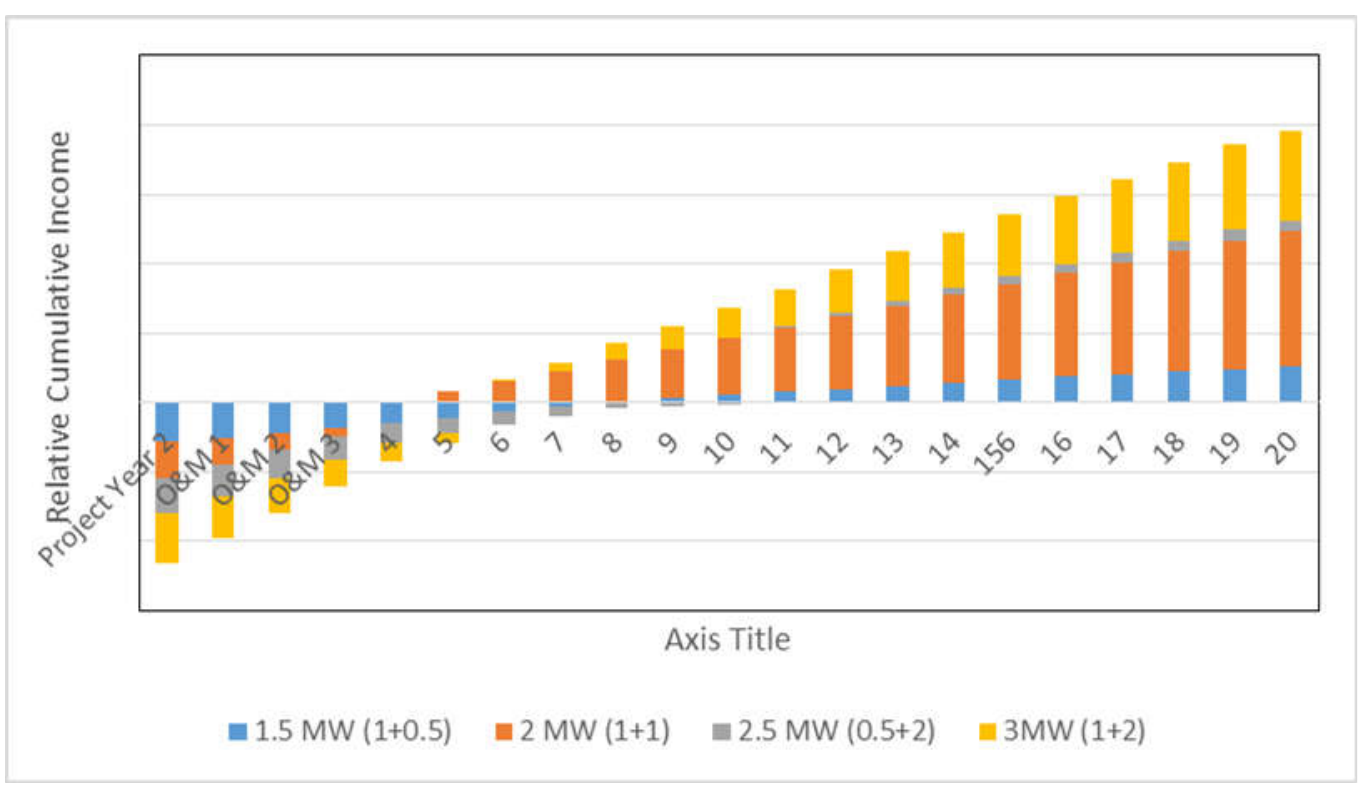

Within the defined financial and spatial constraints, a decision-making simulation was carried out to determine the most economically favourable hybrid system, as shown in Figure 1. It can be seen, the $2 \mathrm{MW}$ hybrid power system, with $1 \mathrm{MW}$ each of solar PV and biomass power generation has the best financial performance among all the low budget projects.

With regard to recent policies in Sri Lanka along with other feasibility considerations and limitations, the $2 \mathrm{MW}$ hybrid power system with 1 MW each from Solar PV and Biomass based gasification system has thus been proposed.

\section{MW Hybrid Power Generation Unit}

The proposed $2 \mathrm{MW}$ hybrid power system, with $1 \mathrm{MW}$ each from solar PV and biomass-based gasification system has been calculated to have the best financial performance among different combinations. The proposed $1 \mathrm{MW}$ biomass power plant is a single downdraft gasifier, with dual $500 \mathrm{~kW}, 8$ stroke internal combustion engine based modular power plant, the primary fuel being dendro (sustainably grown biomass) and coconut waste (husks, shells, etc.).

The two $1 \mathrm{MW}$ units have been proposed to be connected to the same ac bus that will be connected to the grid. Figure 2 shows the scheme.

Figure 2 - Layout of the 2 MW Hybrid System, 1MW each from Solar PV and Biomass Gasification

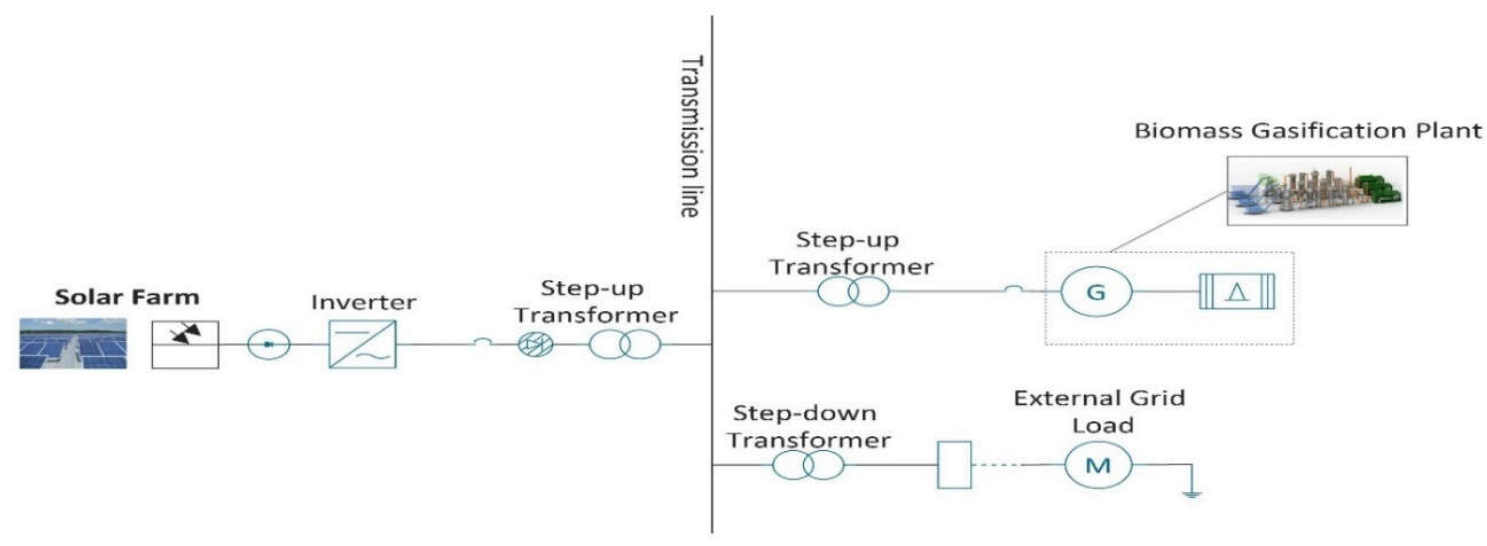


In comparison with individual standalone systems, the hybrid system economics are of considerable interest. The summary of the project cost is provided in Table 1. An acceptable payback period of 4 years with $25.4 \%$ project internal rate of return has been obtained with a proposed solar tariff of $18 \mathrm{LKR} / \mathrm{kWh}$, lower than the highest allowable bid of $22 \mathrm{LKR} / \mathrm{kWh}$. Thus, even with a lower solar tariff, due to hybridization, the project developer would have considerable advantages for the $1 \mathrm{MW}$ solar projects over bidders with standalone systems.

Table 1 - Summary of the Hybrid Power Plant Economics

\begin{tabular}{|l|c|}
\hline Parameter & Value \\
\hline Project CAPEX (million USD) & 2.45 \\
Proposed Solar Tariff (LKR/kWh) & 18.00 \\
Project IRR & $25 \%$ \\
Debt Equity Ratio & $70: 30$ \\
Payback period (years) & 4 \\
\hline
\end{tabular}

\section{Sensitivity Analysis}

To analyze the robustness of the base case scenario, the following sensitivity analyses were conducted. The sensitivity analyses include Dendro and paper as feedstock for biomass power plant, varying debt and equity ratio, fuel cost and solar power purchase agreements.

The results are given in Table 2. A lower capacity factor of the biomass power plant, resulting from inefficient supply of feedstock would significantly lower the project returns. The cost of biomass feedstock, also resulting from an inefficient supply chain has negative impacts on the project economics. As calculated, a 30\% rise in the price of feedstock would cause the project returns to drop, even though the payback period remains constant at 4 years.

Table 2 - Results of Sensitivity Analysis

\begin{tabular}{|ccccccc|}
\hline Sensitivity Case & $\begin{array}{c}\text { Base } \\
\text { Case }\end{array}$ & $\begin{array}{c}\text { Biomass } \\
\text { Capacity } \\
\mathbf{7 0 \%}\end{array}$ & $\begin{array}{c}\text { Cap Factor } \\
\mathbf{5 0 \%}\end{array}$ & D:B 60:40 & D:B 80:20 & $\begin{array}{c}\text { Fuel Cost 8 } \\
\text { LKR/kg }\end{array}$ \\
\hline $\begin{array}{c}\text { Project IRR (\%) } \\
\text { Equity IRR (\%) }\end{array}$ & $25.0 \%$ & $30.0 \%$ & $18.8 \%$ & $25.6 \%$ & $24.3 \%$ & $21.4 \%$ \\
$\begin{array}{c}\text { Net Present Value } \\
\text { (MUSD) }\end{array}$ & 2.31 & $47.3 \%$ & $24.6 \%$ & $34.5 \%$ & $37.5 \%$ & $29.5 \%$ \\
$\begin{array}{c}\text { Pay Back Period (yrs.) } \\
\text { Net revenue earned in 20 }\end{array}$ & 4 & 3.38 & 1.25 & 2.16 & 2.48 & 4.67 \\
years (MUSD) & 8.98 & 11.89 & 6.06 & 9.17 & 8.78 & 4 \\
\hline
\end{tabular}

Table 3 - Results of Sensitivity Analysis with varying Solar Power Purchase Agreement (PPA)

\begin{tabular}{|c|c|c|c|c|c|c|}
\hline Sensitivity Case & $\begin{array}{l}\text { Base } \\
\text { Case }\end{array}$ & $\begin{array}{c}\text { PPA } 5 \\
\text { LKR/kWh }\end{array}$ & $\begin{array}{l}\text { PPA 10 } \\
\text { LKR/kWh }\end{array}$ & $\begin{array}{l}\text { PPA 14 } \\
\text { LKR/kWh }\end{array}$ & $\begin{array}{l}\text { PPA 16 } \\
\text { LKR/kWh }\end{array}$ & $\begin{array}{c}\text { PPA 20 } \\
\text { LKR/kWh }\end{array}$ \\
\hline Project IRR (\%) & $25.0 \%$ & $19.8 \%$ & $21.8 \%$ & $23.4 \%$ & $24.2 \%$ & $25.8 \%$ \\
\hline Equity IRR (\%) & $35.8 \%$ & $26.2 \%$ & $29.8 \%$ & $32.8 \%$ & $34.3 \%$ & $37.4 \%$ \\
\hline Net Present Value (MUSD) & 2.31 & 1.4 & 1.78 & 2.05 & 2.18 & 2.45 \\
\hline Pay Back Period (yrs.) & 4 & 5 & 4 & 4 & 4 & 3 \\
\hline $\begin{array}{c}\text { Net revenue earned in } 20 \\
\text { years (MUSD) }\end{array}$ & 8.98 & 6.69 & 7.78 & 8.07 & 8.62 & 9.33 \\
\hline
\end{tabular}


An additional sensitivity study with respect to solar PV tariff within the hybrid system was carried out and presented in Table 3. As shown, the solar tariff can be as low as $10 \mathrm{LKR} / \mathrm{kWh}$, while maintaining a project payback of 4 years. This is only possible due to the hybridization of the solar PV with biomass gasification power plant, where the biomass power plant, producing a higher share of energy, provides economic resilience to the operation of the PV plant.

\section{Operation Strategy}

Since both the power plants have individual plant factors and grid restrictions, the operation strategy can be fixed to supply 1 MW constantly to the grid. A stable power supply can thus be supplied to the grid. This is additionally assisted by the selection of an internal combustion (IC) engine-based power generation system from biomass.

Project experience from different industries show that these engines have increased the modularity of power generation units over traditional turbine-based systems. In addition to having very high part load efficiency, combustion engines have faster ramp rates and shorter start times with respect to traditional gas turbine systems. These features result in achieving a high ramping capacity with the IC engine-based power generation units, primarily for upstream ancillary services - and, consequently, a reduced marginal cost of provision of those ancillary services.

Whenever the solar radiation is sufficient for the solar plant, the plant is operated at its full capacity. During this period, the biomass power plant can be shut down. After sunset, however, the biomass plant will be operating at full capacity. Both the plants being connected to the common ac bus on the generation side, a relatively stable $1 \mathrm{MW}$ power can be supplied to the grid. Considering $1 \mathrm{MW}$ power supplied to the grid, a capacity factor of around $75 \%$ can be achieved, which would else be only $17.5 \%$ with respect to a standalone solar PV system.

Although the plants are a single hybrid plant, power purchase agreements for both the plants are set individually. Ceylon Electricity Board (CEB) offers separate tariffs for solar based power plants and biomass-based power plants and both are variable on the long run. The system however may provide added benefits of maintaining grid flexibility and stability when the Ceylon Electricity Board (CEB) would decide to offer incentives and bonus for utilities for both the parameters.

\section{Environment Impact Assessment}

Environment impact analyses show that the impact of implementing a hybrid power plant on biotic and abiotic resources is not severe. Social impacts and alteration of the local living patterns are considerable, that include the impacts in preconstruction, construction and operational stages. Flooding, clearing vegetation, impact to the utility supplies are to be expected in the preconstruction stage. Excessive land usage, impact on road traffic in the area, impact on flora, fauna and habitat, soil degradation can occur during the construction stage. Water usage, logistics, drainage, harmful fumes, hazardous materials, visual impacts, dust, noise and social impacts are potential impacts in the operational stage. Major physical, mental and social impacts due to the power plants were analysed in the health impact assessment and were not found to be critical.

Several mitigatory measures, can however be proposed, that can include but not limited to public consultation and information disclosure, community development, improving public utilities, establishment of construction camps and offices etc.

\section{Carbon Dioxide Mitigation}

Emission from a solar PV power plant is considered zero since the life cycle emissions were neglected in the study. The current grid emission factor of Sri Lanka is 768.9 grams $\mathrm{CO}_{2}$ per $\mathrm{kWh}$. Therefore, net generation of $1.5 \mathrm{GWh}$ of solar energy would result in the mitigation of approximately 1068 tons of carbon dioxide.

Recent studies in Sri Lanka for biomass-based power plants show that a mitigation of $80 \%$ of emissions is feasible. Even though the power generated can be said to be clean, the emissions from production, collection and transportation of biomass have been included to evaluate the net emissions from the system.

Therefore, the $2 \mathrm{MW}$ hybrid power system can reduce at least $80 \%$ of the emissions from the printing process.

\section{Conclusions}

According to the study, the use of wind energy conversion to meet the power demand of the company is not feasible for technical reasons as well as for environmental and economic reasons. It was also observed that a solar and biomass hybrid system is the best option for availability of resources as well as economics, rather than 
using a single source. Therefore, a 2 MW capacity hybrid system incorporating solar photovoltaic and biomass gasification, $1 \mathrm{MW}$ each, is proposed to be the most economical solution, with project capital expenditure of 2.45 million USD.

By implementing the proposed hybrid energy system, an estimated reduction of emissions of at least $80 \%$ could be obtained.

\section{Acknowledgments}

This work has been carried out as an extension of the industry involved academic/professional skill development project "Grand Challenge Project in Sustainable Energy System Development" performed by authors.

The financial, logistical and professional support provided by InnoEnergy (Sweden), and Wijeya Newspapers Ltd. (Sri Lanka) are gratefully acknowledged.

The valuable mentorship of the SELECT Grand Challenge projects generally provided by Professor Torsten Fransson of EIT InnoEnergy, Netherlands is specially acknowledged.

\section{References}

[1] APS Panel on Public Affairs, Integrating Renewable Electricity on the Grid, APS Physics.

[2] K. Jayasekera, Status of Sri Lanka Cross Border Interconnection with India \& Expected Benefits, CEB, Colombo, 2014.

[3] Ceylon Electricity Board, Long Term Generation Expansion Plan, 2015-2034, Ceylon Electricity Board, 2016.

[4] A. S. V. AG, A Life Cycle Assessment of the production of a daily newspaper and a weekly magazine, AXEL SPRINGER VERLAG AG, Zürich, 1998.

[5] Sri Lanka Sustainable Energy Authority, Sri Lanka Energy Balance, 2014. Available at: http:/ / www.info.energy.gov.lk/. [Accessed 22. 03. 2017].

[6] Wikipedia, Decline of newspapers, Wikipedia, 1303 2017. Available at: https://en.wikipedia.org/wiki/Decline_of_n ewspapers. [Accessed 22. 03 .2017].

[7] S. Weerawansa and G. Warushamana, The Traditional Newspaper Industry vs. the Technology Driven News Media - Predatory or Complementary Behaviour: Issues, Trends, Prospects and Emerging Realities of the Print Media faced with Emerging Technological Directions in the Sri Lankan Context, Sunday
Observer, Associated Newspapers of Ceylon Ltd.

[8] A. Withanaarachchi, L. Nanayakkara and C. Pushpakumara, The Progress of Sri Lanka's Renewable Energy Sector Developments in Mitigating the GHG Emission, Energy and Environmental Engineering, Vol. 2, No. 5, pp. 113-119, 2014.

[9] R. Fares, The Price of Solar Is Declining to Unprecedented Lows, Scientific American, 27 082016.

[10] IRENA, Global Solar Atlas, IRENA, Available at: http://irena.masdar.ac.ae/. [Accessed 22. 03. 2017].

[11] M. Deshmukh and S. Deshmukh, Modeling of hybrid renewable energy systems, Renewable and Sustainable Energy Reviews, Vol. 12, No. 1, pp. 235-249, 2008.

[12] Ministry of New and Renewable Energy, Biomass Knowledge Portal, Available at: http://biomasspower.gov.in/. /. [Accessed 22. 03. 2017].

[13] D. Elliot, M. Schwartz, G. Scott, S. Haymes, D. Heimiller and R. George, Wind Energy Resource Atlas of Sri Lanka and Maldives, National Renewable Energy Laboratory, 2003.

[14] Ceylon Electricity Board (CEB), Guide for Grid-Interconnection of Embedded Generators - Part 2, Ceylon Electricity Board (CEB), 2000.

[15] Henrique Garrido, V. Vendeirinho and M. Brito, Feasibility of KUDURA hybrid generation system in Mozambique: Sensitivity study of the small-scale PVbiomass and PV-diesel power generation hybrid system, Renewable Energy, Vol. 29, pp. 47-57, 2016.

[16] K. Janardhan, T. Srivastava, G. Satpath and K. Sudhakar, Hybrid Solar PV And Biomass System For Rural Electrification, International Journal of ChemTech Research, Vol. 5, No. 2, pp. 802-810, 2013. 